\title{
OS INTELECTUAIS E O MÉTODO
}

\author{
LOS INTELECTUALES Y EL MÉTODO
}

THE INTELLECTUALS AND THE METHOD

Francisco Máuri de Carvalho Freitas ${ }^{1}$

\begin{abstract}
Resumo: O presente estudo é uma despretensiosa contribuição à questão do método dialético, enquanto processo de investigação e ordenação lógica de uma determinada atividade, neste caso, a produção do conhecimento. $\mathrm{O}$ objetivo deste estudo é afirmar como tarefa da crítica reportar que na educação física os inimigos do marxismo ao produzirem pesquisas científicas e discursos apologéticos "desinteressados", não engajados, reforçam o papel do Estado capitalista e justificam as perversas estruturas sobre as quais está edificada a cidade do capital. À guisa de conclusão, a crítica marxista é indispensável à desobstrução da retórica positivista ainda hegemônica na universidade pública brasileira que deveria ser espaço de deslegitimação da ordem burguesa e reconstrução do real que se revela como história e cujo conteúdo é o mundo criado pelo trabalho e pela luta do homem contra a natureza. Preferindo viver uma existência vazia de princípios, aceitar como inexorável o quotidiano criticado, mudando de lado diante de insignificantes abalos sociais, os intelectuais da ordem continuam vivendo na ilusão e na quimérica esperança sem ação de um mundo onde eles, iluminados, seriam os portadores da iluminação.
\end{abstract}

Palavras chave: Teoria; Marxismo; Método; Papel dos intelectuais; Crítica.

Resumen: El presente estudio es una despretenciosa contribución a la cuestión del método dialéctico, mientras proceso de investigación y ordenación lógica de una determinada actividad, en este caso, la producción del conocimiento. El objetivo de este estudio es afirmar como tarea de la crítica, reportar que en la educación física los enemigos del marxismo al produjeren pesquisas científicas y discursos apologéticos "desinteresados", no comprometidos, refuerzan el papel del Estado capitalista y justifican las perversas estructuras sobre las cuales está edificada la ciudad del capital. A guisa de conclusión, la crítica marxista es indispensable a la desobstrucción de la retórica positivista todavía hegemónica en la universidad pública brasileña que debería ser espacio de deslegitimación del orden burgués y reconstrucción del real que se revela como historia y cuyo contenido es el mundo creado por el trabajo y por la lucha del hombre contra la naturaleza. Prefiriendo vivir una existencia vacía de principios, aceptar como inexorable el cotidiano criticado, cambiando de lado delante de insignificantes desórdenes sociales, los intelectuales del orden continúan viviendo en la ilusión y en la quimérica esperanza sin acción de un mundo donde ellos, iluminados, serían los portadores de la iluminación.

Palabras-clave: Teoría; Marxismo; Método; Papel de los intelectuales; Crítica.

\begin{abstract}
This study is a no pretentious contribution to the question of the dialetical method, as a process of research and logical ordination of an activity, in this case, the production of the knowledge. The objective of this study is to claim that the task of the criticism is to report that in the physical education the enemies of the marxism when they produce acientific researches and "uninterested" apologetic speeches, not engaged, they reinforce the role of the capitalist State and they justify the perverse structures where is built the city of the capital. As a conclusion, the marxist criticism is indispensable to the clearance of the positivist rhetoric still hegemonic in the Brazilian public university that should be a place for a non validation of the bourgeois order and reconstruction of the real revealed as history and whose content is the world created by the labor and by the fight of men against the nature. Prefering to live an empty of principles existence, to take as inexorable the criticized everyday, changing the side towards the negligible social quakes, the intellectuals of the order keep living on the illusion and on the dreamlike hope without action from a world that they, the enlightened, would have the illumination.
\end{abstract}

Key-words: Theory; Marxism; Method; Role of the intellectuals; Criticism. 


\section{Introdução}

A quase totalidade dos intelectuais ou teóricos da área de Educação Física gosta de circular "ao redor dos tranquilos rebanhos de historiadores que se alimentam nas ricas pastagens de suas fontes primárias ou ruminam entre si suas publicações"2. As controvérsias teóricas mais aguçadas continuam sendo travadas no campo de batalha das metas-narrativas parasitadas por "falsos intelectuais".

Recorrendo ao labirinto conceitual de Antonio Gramsci, segundo o qual todos somos intelectuais, fui levado a recordar que o intelectual orgânico, no sentido gramsciano da palavra, nascido da classe dominante ou da pequena burguesia, é o encarregado de exprimir o espirito objetivo da classe da qual é parte constitutiva.

Para Sartre, intelectual é todo homem e toda mulher que toma consciência da oposição entre ele e a sociedade, entre a pesquisa que pratica com todas as normas que ela implica e a ideologia dominante com seu sistema de valores tradicionais na qual bebeu sobejamente, ainda que disto possa não ter uma compreensão muito clara. O intelectual enquanto produto da sociedade despedaçada "é sua testemunha porque interiorizou seu despedaçamento. É, portanto, um produto histórico".3

Reprovando ser "o que sempre nega", e ignorando que a contestação (negação) não é um traço do caráter, mas um procedimento necessário ao pensamento filosófico e ao pensamento científico, o intelectual colocando o universal a serviço do particular, pratica a autocensura (por insciência ou dolo) e tornase apolítico, agnóstico etc. Pode acontecer ainda que o "poder" o pressione a renunciar a uma atitude de contestação válida, e ao abdicar do seu "poder contestador, diz-se, nesse caso, com satisfação, que ele não é intelectual", mas "um técnico do saber". ${ }^{4}$

Ao contrário, o intelectual é aquele tipo de pessoa que se "recusa a ser agente subalterno da hegemonia e o meio de fins que ignora ou que lhe é proibido contestar, então o agente do saber prático transforma-se num monstro, quer dizer, num intelectual, que se mete no que não é de sua conta" e a contestar o conjunto das verdades recebidas e as condutas que nelas se inspiram, sempre em nome de uma concepção global do homem e da sociedade. ${ }^{5}$

O intelectual, tal como o senso comum o admite, é o sujeito a quem a classe dominante atribuiu de fato e de direito a tarefa específica de elaborar e transmitir conhecimentos, teorias, doutrinas, ideologias, concepções de mundo ou simples opiniões, que acabam por constituir as ideias ou os sistemas de ideias de uma determinada época e de uma determinada sociedade. ${ }^{6}$

Em outras palavras, o intelectual é alguém que não faz coisas, mas reflete sobre as coisas, que não maneja instrumentos ou objetos (nem armas), mas símbolos. É alguém cujos instrumentos de trabalho não são máquinas, mas ideias ${ }^{7}$; ou seja, o intelectual, cuja essência é ser um técnico do saber, é um sujeito específico considerado como criador, portador e transmissor de ideias, a quem o Estado e a burguesia atribuíram de fato e de direito a tarefa especifica de elaborar e transformar conhecimentos, teorias, doutrinas, ideologias, visões de mundo ou simples opiniões, em ideias e sistemas de ideias de uma época e de uma determinada sociedade que atendem aos objetivos da classe dominante. 


\section{Os intelectuais da educação física}

Especialmente na Educação Física, os intelectuais do início do século XXI aspiram às características da vida de uma aristocracia que apesar de sua insignificância política continua a representar o statu quo mais elevado. Devo salientar que a palavra aristocracia (derivada da areté grega e traduzida como virtude, virtue, virtù etc.), cujos significados e conceitos cristãos que lhes foram atribuídos nas sociedades ocidentais provocaram uma grande confusão quando aplicados ao contexto dos gregos antigos, ou seja, causaram e ainda causam sérios problemas de interpretação, à medida que a tradução literal da palavra era excelência, isto é, o ponto máximo de aperfeiçoamento que um determinado homem poderia alcançar.

A descontextualização ou o sistemático recorte de textos cujos contextos continuam ignorados, tem sido uma sistemática na Educação Física. Neste sentido, vale ressaltar que ninguém é intelectual por direito natural ou por direito divino. Por isso, ao ocupar uma posição original privilegiada na sociedade em que vive, não deve reconhecer tal fato como sendo naturalmente reservado a ele e nem determinado por imposição divina.

Assim, a leitura criteriosa e a oitiva atenta dos mais diversos trabalhos e discursos hegemônicos produzidos pela intelectualidade hegemônica na Educação Física, apontaram ao meu escrutínio crítico que a concepscão materialista da história elaborada por Karl Marx e Friedrich Engels é, de longe, o melhor guia para compreender a história e sobre ela realizar os mais diversos estudos. É certamente o melhor guia para aqueles que como eu, entende que o campo de luta acadêmica e política tem sido o da ascensão do capitalismo moderno com implicações e sequelas para o mundo do trabalho.

Sopesando criticamente o que tenho lido e ouvido, gostaria de dizer duas coisas: em primeiro lugar, que não é possível uma discussão sobre a cidade do capital que não se reporte a Marx ou, "mais precisamente, que não parta de onde ele partiu”; em segundo lugar, que em vários setores da Academia há uma clara e sistemática distorção do marxismo para fins irracionais. Os intelectuais, na verdade técnicos do saber, principalmente os mais jovens, quando chafurdam o solo das teorias do conhecimento, o fazem "não para compreender sua sociedade e como ela muda, mas para aprová-la (por insciência ou dolo), orgulharse dela, serem ou se tornarem bons cidadãos (pastichos de intelectual)"

As teorias do conhecimento esposadas, inspiração e ideologia, têm uma tendência embutida a se tornar autojustificação da sociedade da exploração do homem pelo homem. Na melhor das hipóteses, às vezes, aparece como crítica anódina e melíflua do capitalismo. "Não existe venda para os olhos mais perigosa que esta" 10 .

Neste sentido, é tarefa da crítica tentar remover essa venda ou tapa-olhos. Mas, infelizmente, parece que neste início de século a Academia, com todo o mal-estar que a afirmação a seguir possa provocar, não é o locus de remoção de vendas ideológicas, pois, com raras exceções, seus intelectuais são agrupamentos de pessoas para servir à burguesia industrial, fundiária e financeira e justificar as mazelas praticadas nas cidades pelo capital contra o trabalho.

Prova disto são os estudos que li e os de que ouvi relatos. Eles são irremediavelmente assépticos, ou seja, estariam, segundo a vontade dos seus idealizadores, supostamente escoimados de pré- 
noções e juízos de valor. Sobre tal pretensão, saliento que entre os intelectuais mais rigorosos há uma "proposição geral, e até agora virtualmente incontroversa, de que é impossível uma ciência puramente objetiva e isenta de juízos de valor"11.

Para os intelectuais da Educação Física, com raras exceções, parece ser "menos perigoso para a ciência, e para uma análise política e cientificamente fundamentada, saber que se está praticando supressio veri ou mesmo suggestio falsi, que convencer a si mesmo que as mentiras são, em certo sentido complexo, verdade" 12 .

Sobre os estudos que li e os de que ouvi relatos, ainda diria que são descritivos do começo ao fim, não tendo, portanto, um laivo sequer da mais comezinha crítica à realidade social e econômica. É como se tivessem sido produzidos ao sabor idiossincrático dos seus autores, os quais não guardam nenhuma vinculação com as classes sociais ou frações de classes. É como se fossem elaborados por atores de outros planetas: simplesmente desconsiderando o momento político e econômico no qual e a partir do qual produziram seus estudos.

Do ponto de vista da crítica dura, os estudos que li e os relatos que ouvi, não ajudam os leitores e os ouvintes atentos entenderem a realidade na qual foram elaborados. Os autores simplesmente não tecem comentários, nem mesmo um aligeirado esboço sobre a conjuntura política de sua época. $\mathrm{Na}$ ausência da crítica percuciente, os leitores e ouvintes não conseguirão, nem com muito esforço, localizar os nexos entre educação física, esportes, lazer, política e economia, fato este que continua a reafirmar no interior da educação física enquanto área do conhecimento humano ou faceta cultural, a hegemonia do pensamento positivista.

Nesta área condena-se sem compreender, ou seja, persevera a profunda ignorância sobre os fatos e a manifestação descabida do senso comum contra a concepção de mundo que caminha na contramão do capital. Infestados ao longo de sua vida familiar, escolar, religiosa e social, os intelectuais da Educação Física de forma bisonha continuam manipulando os mais esdrúxulos preconceitos sobre o marxismo.

A rigor, inimigos do marxismo, esses intelectuais, ao produzirem seus "papers", pesquisas científicas e discursos apologéticos "desinteressados" ou não engajados, fazem reforçar o papel do Estado e justificar as fundações da cidade do capital.

\section{Sobre o Método}

O presente estudo é uma despretensiosa contribuição à questão do método dialético, à elaboração do qual o autor toma como ponto de partida a compreensão de que o verbete método provém do grego méthodos ("metá" - atrás, através e "hodós" - caminho), aceito como sendo um processo de investigação ou ordenação lógica de uma determinada atividade, neste caso, a produção do conhecimento. Todavia, considero de bom alvitre não confundir método com metodologia, esta do ramo da lógica que se dedica ao estudo dos métodos. A rigor, 
[...] as palavras que terminam com 'logia' apresentam uma característica peculiar: 'logia' significa a ciência ou estudo de algum fenômeno, mas, em virtude de um curioso processo de inversão, as palavras assim terminadas passaram, em muitos casos, a significar o fenômeno estudado, mais do que o conhecimento sistemático do próprio fenômeno. Assim, por exemplo, ' metodologia' significa o estudo do método, mas é normalmente empregado hoje em dia para referir-se ao próprio método. ${ }^{13}$

A palavra método significa processo ou conjunto de processos

Que permite conhecer determinada realidade, produzir certo objeto ou desempenhar este ou aquele tipo de comportamento. Grosso modo, confundido com a noção de processo, de meio ou via empregada na consecução de determinado objetivo ou na produção de determinado fenômeno, o método ainda é coincidente com a noção de técnica empregada para alcançar um objetivo preestabelecido ${ }^{14}$.

Por exemplo, o método dialético, no campo político, é um contraponto às fontes metodológicas do pensamento positivista e quejandos que tornam monótona a Academia, procurando dissimular as contradições sociais e a luta de classes para ratificar e reproduzir a moderna e mórbida sociedade de classes.

Nas ciências sociais, diferentemente das ciências da natureza, o pesquisador está enredado na trama social, de forma direta ou indireta, isto é, ele está perpassado pelas contradições da realidade objetiva na qual todas as relações sociais apresentam-se nebulosas. Enquanto nas ciências da natureza se os resultados podem ser ditos como sobre as classes, o uso e a interpretação que deles são tirados estão marcados com um selo de classe. Sob esta ótica, é preciso redimensionar a função social do investigador para, descobrindo-a anacrônica, cauterizá-la por representar um obstáculo à edificação de consciências críticas da totalidade no seio do conjunto da classe operária e demais trabalhadores assalariados. O pesquisador, ainda que não necessariamente pertença à área em que está surgindo o seu "objeto" de interesses e de estudo e análise, não consegue eximir-se de agir no sentido do seu equacionamento: ratificando-a ou transformando-a.

O investigador enquanto animal político e, portanto, um animal social, ou procura esclarecer as interrogações postas pela própria dinâmica sócio-histórica do desenvolvimento das forças produtivas de um determinado modo de produção, ou trabalha no sentido de obscurecer a compreensão da maioria esmagadora da sociedade sobre o desenvolvimento das forças produtivas. As interrogações que faz são, em última instância, determinadas pelas relações sociais de produção que, nesta sociedade, são as relações de produção capitalistas.

Por mais que se afirme a existência de vários métodos, em linguagem filosófica dir-se-á existirem apenas dois: o método dialético e o método idealista. Este método tem como ponto de partida o homem pensado, imaginado, idealizado, o homem que pensa divorciado da história e da natureza. No método idealista o pesquisador rompe a ligação inquebrantável entre os "sujeitos" e os "objetos", entre a história dos fatos econômicos e sociais e a história das ideias; ele nega ainda o caráter total da atividade humana (teoria/prática) historicamente construída na e pela transformação da natureza.

A propósito, "o processo do conhecimento científico é um fato humano histórico e social. Sendo as tentativas de separar seus aspectos 'material' e espiritual no melhor dos casos, senão abstrações 
provisórias, sempre implicando em grande perigo para o conhecimento"15. Por outro lado, o método dialético, ao mesmo tempo, material e intelectual, cinde-se em dois: o método de investigação e o método de exposição.

O primeiro indica como o sujeito deve abordar um objeto que está a reconhecer ou a transformar e que operações mentais ou práticas precisa realizar para alcançar o objetivo pretendido. $\mathrm{O}$ método de investigação está ideologicamente fundamentado para influir na consciência da classe operária e não apenas para servir de camuflagem às contradições sociais entre as classes. Representa o universal concreto, e ao revelar tanto as leis do movimento real, quanto do movimento do pensamento ${ }^{16}$, trabalha ainda na captação da unidade do movimento que engendra os contraditórios, que os opõe, que faz com que se choquem, quebrando-os ou superando-os ${ }^{17}$.

Pautado em princípios universais, o método dialético é a um só tempo rigoroso e o mais fecundo por sua capacidade de detectar as múltiplas faces e conexões das coisas e dos fenômenos sociais, ou seja, os aspectos mediante os quais as coisas são vulneráveis/transformadas pela prática social ${ }^{18}$. Nesta discussão o concreto nem sempre fica muito claro, entendido como a interconexão objetiva das partes do fenômeno, o conhecimento como reflexo dessa interconexão que produz o conteúdo real do objeto ${ }^{19}$. A restauração do método dialético de Hegel é elaborada por Marx despojando-o de sua roupagem idealista, colocando-o como única forma exata do desenvolvimento do pensamento ${ }^{20}$.

Ao contrário do que apregoam os usuários do método idealista, o método dialético não é neutro ou apolítico, mormente porque na sua forma racional causa horror à burguesia e aos porta-vozes do seu ridículo doutrinário. Para esse método a "sua concepção do existente, afirmando-o, encerra, ao mesmo tempo, o reconhecimento da negação e da necessária destruição dele"21. Ele "apreende, de acordo com seu caráter transitório, as formas em que se configura o devir; porque, enfim, por nada se deixa impor, e é, na sua essência, crítica e revolucionária"22.

O método dialético é abominado pela burguesia por situar-se na perspectiva da classe operária e apreender as formas ideológicas e as formas objetivas que cada sociedade de classes assume no decorrer de sua história, como transitórias, históricas, perecíveis ${ }^{23}$. Para Lenin, o método dialético é tributário e indissociável da obra de Marx e Engels, suscitando à burguesia uma hostilidade indisfarçável à medida que vê "no marxismo uma espécie de seita perniciosa. E não se poderia esperar outra atitude, pois numa sociedade calcada na luta de classes não há intelectual e cientista social imparcial’24.

Vejam bem. Se por um lado as ciências sociais, vazadas pela ideologia liberal, defendem por caminhos diversos a escravidão assalariada, por outro, o marxismo continua declarando guerra implacável à sociedade capitalista, sociedade da escravidão. Neste sentido, esperar que intelectuais e cientistas sejam imparciais enquanto membros ativos da sociedade do escravismo assalariado é ingenuidade pueril, tanto quanto acreditar que a burguesia elevará os salários dos seus operários e trabalhadores às expensas da redução dos seus lucros ${ }^{25}$.

A rejeição ao método dialético tem sido a prática dos intelectuais que fazem suas carreiras refutando o marxismo: anacrônicos guardiões do legado dos sistemas caducos e das teorias novidadeiras, se lançam contra o marxismo, a revolução e o comunismo com o mesmo zelo ${ }^{26}$. O que choca os 
intelectuais da ordem é que ao assumir o método dialético, quem o faz assume também a perspectiva da luta de classes, ou seja, além de se postar ao lado dos trabalhadores urbi et orbi, demarca seu rompimento com o pensamento acadêmico oficial entendido como instrumento à justificação da reprodução das relações de produção modais.

Apesar do pragmatismo, do positivismo, da fenomenologia e do existencialismo, o marxismo é capaz de aglutinar os conhecimentos parcelares de tal forma que é impossível tornar abstrata sua dimensão filosófica, sua raiz econômica e determinação política, e enquanto pesquisa sobre a existência e consciência, sobre o conhecimento verdadeiro e falso, (Marx insistia em dizer não existir verdade abstrata, a verdade é sempre concreta), sobre o possível e o impossível27.

Para além da contrafação, o pesquisador, ao situar-se na perspectiva da totalidade, precisa de uma filosofia e uma forma de reflexão, pensamento e conhecimento rigoroso que não lida com abstrações e, mesmo quando isola ou destaca o objeto, o faz para efeito didático, porque "jamais perde a consciência de que o objeto abstraído só é o que é, só tem sentido, enquanto integrado em seu contexto, na totalidade de que faz parte" 28 .

Ao eleger a especificidade do conhecimento, por exemplo a Educação Física à condição de totalidade, o pesquisador está a trabalhar sobre uma teoria vazia, abstraída do real. Essa posição representa, precisamente, a negação da dialética materialista histórica e a afirmação das ciências sociais como ingênuas, à medida que não põem em questão, não criticam seus postulados, ou condições de possibilidade 2 . Trabalhando sob a égide da "objetividade científica", o pesquisador apenas se limita

[...] à demonstração da inevitabilidade e da necessidade do processo e não procura revelar em cada estágio concreto desse processo a forma do antagonismo de classe que lhe é própria - objetivismo que caracteriza o processo em geral separadamente das classes antagônicas de cuja luta o processo resulta ${ }^{30}$.

Contra a "objetividade científica" limitada à análise "desinteressada" e, por não dizer, desapaixonada do destino da humanidade, está posta a orientação classista das ciências sociais e da filosofia. Destarte, essa "objetividade" predicada pelas ciências sociais corresponde à camuflagem dos interesses de classe da burguesia exercitando-se na extorsão da força de trabalho alheia.

O procedimento metodológico é, em primeiro lugar, o método de pesquisa sob o qual o pesquisador procura "apoderar-se da matéria, em seus pormenores, de analisar suas diferentes formas de desenvolvimento, de perquirir a conexão íntima que há entre elas. Só depois de concluído esse trabalho, é que se pode descrever, adequadamente, o movimento real"31. Só depois de concluído esse trabalho lhe será possível apresentar adequadamente, no plano ideal, o resultado da pesquisa ou a obra perquirida, grosso modo dando a impressão de uma construção arbitrária, a priori32.

Uma pesquisa séria deverá pautar-se para sua elaboração e conclusão, em duas partes: a primeira, a investigação, a segunda, a exposição essencialmente crítica da realidade histórica perquirida ou do "objeto" de estudo. Vale reportar, esta exposição é essencialmente crítica

[...] porque ela só reconstitui a totalidade sistemática das determinações do capital, através da sistematização da sua estrutura e de seu movimento contraditórios, a partir da pretensão de dominação total do capital sobre o trabalho e de seu malogro sistêmico 
(crise), visto que o capital depende do trabalho, formalmente, enquanto trabalho assalariado e materialmente, enquanto trabalho objetivado, morto, constitui o único conteúdo social do capital. Enquanto exposição das contradições do capital ela é essencialmente crítica ${ }^{33}$.

No Posfácio à segunda edição d'O capital lê-se que “o ideal não é mais do que o material transposto para a cabeça do ser humano e por ela interpretada" 34 . Por isto, é mister descobrir a substância racional no interior do invólucro místico das concepções metodológicas em voga na academia.

O método de exposição enquanto objetivo da apresentação final do trabalho científico é a demonstratio, por exemplo, de que determinada sociedade de classes, como o Janus romano, tem duas faces das quais se conhece apenas uma, a revelada, em que a liberdade, a igualdade e a propriedade representam seu apanágio, enquanto, a outra face, na qual está a não-liberdade, a não-igualdade e a não-propriedade, perfazem uma totalização que dissociada revela apenas

[...] a ilusão criada pela circulação das mercadorias, que deixa apenas perceber a realidade como que um aglomerado de indivíduos proprietários de mercadorias e, portanto, sem o registro de nenhuma memória de como um obteve suas mercadorias, a não ser a impressão de que todos trabalharam para se tornarem proprietários ${ }^{35}$.

A análise sociológica séria não pode ficar restrita a simples descrição do temário perquirido, mas deve se estribar em bases filosóficas e científicas sólidas, mormente aqueles que afirmam a dinamicidade, a temporalidade e a cognoscibilidade das coisas e dos fatos sociais. Essa "análise" deve conduzir o pesquisador a trabalhar sob um paradigma metodológico que aponta a possibilidade do conhecer e explicar de modo coerente, lógico e racional, o fenômeno estudado e suas necessárias e inderrogáveis transformações em fenômenos mais desenvolvidos. Para além da leitura meramente argumentativa ou da hermenêutica descritiva, é preciso assumir a interpretação/análise/transformação das relações de produção, ou seja, transformação radical da sociedade.

Desvelando o núcleo místico das ilações e exegeses fracionadas do quotidiano (a Educação Física, por exemplo), é preciso esquadrinhar as leis que regem a sociedade com o método de investigação buscando esclarecer as ideias e teorias como sustentáculos da produção material; o modo que essas ideias políticas, jurídicas, filosóficas, religiosas etc., as formas ideológicas sustentam o modus vivendi burguês. Ademais deve estabelecer uma série de questões sobre a existência de um "método absoluto" e se tal método não seria uma "abstração do movimento".

Deverá inquirir ainda o que vem a ser "a abstração do movimento". Seria

[...] o movimento em estado abstrato. Que é o movimento em estado abstrato? A fórmula puramente lógica do movimento ou o movimento da razão pura. Em que consiste o movimento da razão pura? Em situar-se em si mesma, opor a si mesma e combinar-se consigo mesma, em formular-se como tese, antítese e síntese, ou bem em afirmar-se, negar-se e negar sua negação ${ }^{36}$.

Ao aplicar o método absoluto à realidade objetiva, as relações de produção e as relações sociais aparecerão engendradas a partir de si mesmas. Aqui está o nó que não se consegue desatar: ao anular a contradição, a luta entre a tese e antítese, a luta de classes, credita-se à criação e transformação da realidade uma cabeça cheia de razão. Nesse sentido, o pesquisador, como Hegel, cai "na ilusão de conceber o real 
como o resultado do pensamento, que se encontra em si mesmo, se aprofunda em si mesmo e se movimenta por si mesmo" 37 .

O estribo filosófico do método é a chave do conhecimento que relaciona a Educação Física, os esportes e as atividades de lazer com as contradições sociais e materiais da sociedade brasileira. A Educação Física e os esportes não podem ser compreendidos a partir de meras e programáticas políticas de governo. Eles têm que estar inseridos na solução técnica e revolucionária dos problemas econômicos e sociais.

O método deve ser a um só tempo, prática e teoria, "totalidade"38. Deve ainda buscar a ligação, a unidade, o movimento que engendra os contraditórios, que os opõe, que faz com que se choquem, que os quebra ou os supera. Com o uso desse método no exame e análise minuciosa da estrutura social capitalista, é possível perceber e compreender que as condições econômicas, isto é, a própria estrutura das forças produtivas, criam as contradições entre grupos correntes, classes sociais antagônicas e nações imperialistas ${ }^{39}$.

O estudo do movimento dialético, portanto, contraditório, impulsiona o pesquisador ao querer resolver as contradições da sociedade ${ }^{40}$. Mas, para tanto, é precioso observar as seguintes regras práticas:

1) Dirige-se sempre ao próprio fenômeno, nesse caso o capitalismo, quer dizer, ele não trabalha sobre digressões, analogias inúteis, contemplações, mas sob a análise objetiva, isto é, análise concreta da situação concreta.

2) Apreender o conjunto das conexões internas do modo de produção capitalista, de seus aspectos; o desenvolvimento e o movimento que lhes são imanentes; pari passu, apreende o capitalismo como totalidade e unidade dos contraditórios, vazado por contradições antagônicas inexoráveis;

3) Analisar o conflito interno das contradições, movimentos e tendências, além do que não esquece que tudo se relaciona, com outras palavras, tudo está ligado a tudo. Mais: não esquece as transições dos aspectos e contradições, passagens ou transições no devir.

4) Não dispensar a apreensão, em si mesmo, de cada fenômeno estudado, proporcionando a construção de um quadro geral norteador do conhecimento de cada realidade.

A dinâmica da investigação sobre a Educação Física, por exemplo, revela elementos contraditórios distribuição e consumo dos produtos culturais. Assim, não compreendemos que produção, distribuição e consumo são inseparáveis. A análise mais acurada permite, então

[...] reencontrar movimento real no seu conjunto, portanto, expor e compreender a totalidade concreta que ora se apresenta, isto é, a atual estrutura econômica e social. O conhecimento desta realidade, através dos seus momentos históricos e do seu dever, é um fruto do pensamento, mas, de maneira alguma, uma reconstrução abstrata, realizada por um pensamento que acumulasse conceitos desligados dos fatos, das experiências e dos documentos ${ }^{41}$.

Para fechar, gostaria de dizer que há ainda caminhos a percorrer que justificam a crítica marxista:

Primeiro, reafirmar a perspectiva da totalidade (o "todo social") como característica do marxismo, inderrogável paradigma oposto ao positivismo, ao falsificacionismo cientificico ${ }^{42}$ e à deformação 
científica ${ }^{43}$, evidenciados na afirmação sobre purificar a educação daquilo que, por hipótese, nada teria a ver com a educação: o econômico, o político e o ideológico.

Segundo, encetar a crítica acerba a dissociação das partes, ratificando a irredutibilidade da imediatidade fenomênica a momentos da prática sem teoria ou de uma teoria sem prática, calcada na parolagem e na erudição retórica a ignorar que o particular não existe senão na medida em que se vincula ao geral e o geral só existe no particular e por meio dele. Sob essa medida, enfatizaremos que não se pode "chegar a uma totalidade que não seja ela mesma elemento ou parte"44. Mesmo porque, o conhecimento da realidade objetiva enseja "uma perpétua oscilação entre o todo e as partes que devem se esclarecer mutuamente" $" 45$.

Terceiro, evidenciar a força de trabalho coletivo: explorada, esmagada e desumanizada, como xeque-mate à pregação dos neoliberais sobre a melhora da qualidade de vida do proletariado que, na verdade, ratifica a tríade dominação, opressão, espoliação.

A crítica marxista é indispensável à desobstrução da retórica positivista ainda hegemônica no interior da universidade pública brasileira por nós entendida como espaço possível de deslegitimação da ordem burguesa e reconstrução do real que se revela como história

[...] cujo conteúdo é a cultura, é o mundo criado pelo trabalho e pela luta do homem [...] a realidade na qual o homem se encontra é a história, pois sua concepção ou visão da natureza, que determina suas relações com o mundo físico, é também um produto da história ${ }^{46}$.

Quarto, desvelar a impossibilidade de escoima da educação das ideologias ${ }^{47}$ construídas no processo dinâmico da luta de classe contra classe.

Quinto, evidenciar o fato de que a prática política educacional acorde com a ideologia dominante que não atende indistintamente aos sonhos e desejos de todos os indivíduos de uma determinada sociedade capitalista.

Os trabalhos que li e os de que ouvi relatos, não consideram as contradições sociais e econômicas, materiais e intelectuais como fulcro concreto do seu suposto objetivo em explicitar e separar a realidade da fantasia. Ainda que os autores possam negar (e certamente negarão!), a vinculação desses estudos ou pesquisas à família comteana é inegável, pois se trata de pesquisas encimadas na falsa "objetividade científica", ou seja, o tratamento dos dados estaria despido e escoimado de quaisquer ideologias. Resgata-se assim, o mito da neutralidade científica.

Quase ao final desta despretensiosa colaboração à polêmica acadêmica, vou repetir, como tenho feito sempre: continuo sintonizado com uma fala de Marx que há muito prendeu minha atenção e me fez compreender mais claramente a atuação dos intelectuais e dos filósofos no interior desta sociedade. É fato que eles

Não brotam da terra como cogumelos, eles são frutos da sua época, do seu povo, cujas energias, tanto as mais sutis e preciosas como as menos visíveis, se exprimem nas idéias filosóficas. O espírito que constrói os sistemas filosóficos no cérebro dos filósofos é o mesmo que constrói os caminhos de ferro com as mãos dos trabalhadores. A filosofia não é exterior ao mundo ${ }^{48}$. 
Posta a fala do oráculo Mouro, para finalizar devo dizer que no intestino da Universidade há um cientificismo célere a comandar uma descabida pretensão dos doutores em ignorar o capital e suas imposturas ideológicas. Preferindo viver uma existência vazia de princípios, aceitar como inexorável o quotidiano criticado, mudando de lado diante de insignificantes abalos sociais, os "críticos" de Marx continuam vivendo na ilusão e na quimérica esperança sem ação de um mundo onde eles, iluminados, sejam os portadores da iluminação. Que tristeza!

\section{Notas}

${ }^{1}$ Doutor em Educação pela UNICAMP. Docente do Cento de Educação Física e Desporto - UFES. Email: chicomauri@hotmail.com

2 HOBSBAWM, E. Sobre a bistória. São Paulo: Companhia das Letras, 1998. p. 7.

${ }^{3}$ SARTRE, J. P. Em defesa dos intelectuais. São Paulo: Ática, 1994. p. 30-31.

${ }^{4}$ Ibidem, p. 29.

5 Ibidem, p. 29.

${ }^{6}$ BOBBIO, N. Os intelectuais e o poder. São Paulo: Unesp, 1997. p. 110.

${ }^{7}$ Ibidem, p. 110.

${ }^{8}$ HOBSBAWM, op. cit., p. 43.

${ }_{9}^{9}$ Ibidem, p. 47.

10 Ibidem, p. 48.

${ }^{11}$ Ibidem, p. 139.

12 Ibidem, p. 145.

${ }^{13}$ EAGLETON, T. Ideologia: uma introdução. São Paulo: Ed. da Unesp; Boitempo, 1997. p. 65.

${ }^{14}$ CORBISIER, R. Enciclopédia filosófica. Rio de Janeiro: Civilização Brasileira, 1987. p. 206.

${ }^{15}$ GOLDMANN, L. Dialética e cultura. Rio de Janeiro: Paz e Terra, 1986. p. 27.

${ }^{16}$ LEFÉBVRE, H. Lógica formal / lógica dialética. Rio de Janeiro: Civilização Brasileira, 1975. p. 237.

${ }^{17}$ Ibidem, p. 238.

${ }^{18}$ Ibidem, p. 241.

${ }^{19}$ LLANOS, A. Introdução à dialética. Rio de Janeiro: Civilização Brasileira, 1988. p. 144.

${ }^{20}$ Ibidem, p. 141.

${ }^{21}$ MARX, K. O capital. São Paulo: Difel, 1982. t, 1 pt. 1, p. 17.

22 Ibidem, p. 17.

${ }^{23}$ LÖWY, M. Método dialético e teoria política. Rio de Janeiro: Paz e Terra, 1975. p. 32.

${ }^{24}$ LENIN, V. I. Obras escolbidas. Moscou: Progresso, 1977. t. 1, p. 35.

${ }^{25}$ Ibidem, p. 35.

${ }^{26}$ Ibidem, p. 40.

${ }^{27}$ LEFÉBVRE, H. A vida quotidiana no mundo moderno. Lisboa: Ulisséia, 1968. p. 23.

${ }^{28}$ CORBISIER, R. Filosofia política e liberdade. Rio de Janeiro: Paz e Terra, 1978. p. 24.

${ }^{29}$ Ibidem, p. 22.

${ }^{30}$ LENIN, V. I. Obras completas. Moscou: Progresso, 1983. t. 1, p. 526.

31 MARX. O capital, op. cit., p. 16. 
32 Ibidem.

${ }^{3}$ MÜLLER, L. M. Exposição e método dialético em o capital. Boletin SEAF, Belo Horizonte, n. 2,. p. 19, 1982.

34 MARX. O capital, op. cit., p. 16.

35 TEIXEIRA, F. J. S. Pensando com Marx. São Paulo: Ensaio, 1995. p. 41.

36 MARX, K. Miséria de la filosofia. Moscú: Progreso, 1979. p. 86.

${ }^{37}$ MARX, K. Contribuição à crítica da economia politica. São Paulo: Martins Fontes, 1983. p. 219.

${ }^{38}$ LEFÉBVRE, H. O marxismo. São Paulo: Difel, 1979. p. 9.

${ }^{39}$ Ibidem, p. 238.

40 Ibidem.

${ }^{41}$ Ibidem, p. 32.

${ }^{42}$ Interpretação mecanicista que ignora a realidade dinâmica da história, da sociedade do desenvolvimento humano, isto é, dos homens e mulheres concretas inseridas e determinadas / determinantes de uma dada sociedade.

43 Para Goldmann "a deformação científica [...] se encontra no fato de se considerar essa comunidade como objeto de estudo" (GOLDMANN, L. Ciências humanas e filosofia. São Paulo: Difel, 1980. p. 22).

${ }^{44}$ Ibidem, p. 11.

45 Ibidem, p. 4.

46 Ibidem, p. 31.

47 Conjuntos de idéias, teorias e pensamentos subjacentes, em última instância determinantes, das concepções de mundo (Weltanschaunngen) e dos projetos de sociedade também antitéticos das classes sociais de uma dada sociedade.

${ }^{48}$ MARX, K. Escritos de juventud. In MARX, K.; ENGELS, F. Obras fundamentales. México: Fondo de Cultura Económica, 1987. t. 1. p. 230. 